\title{
The Relationships between Vocabulary Learning Strategies and Vocabulary Size among Adult Spanish Foreign Language Learners
}

\author{
Dieter A. Waldvogel \\ United States Air Force Academy, Colorado Springs, CO, U.S.A.
}

\begin{abstract}
The aim of this study is to investigate the relationships between the type of vocabulary learning strategies (VLS) adult Spanish foreign language (FL) students use at different levels of proficiency and their vocabulary size. A total of 475 college students enrolled in Spanish courses at the beginning, intermediate, and advanced proficiency levels participated in this study. The data were analyzed through quantitative methods using two measuring instruments: a vocabulary learning questionnaire used to discover students' VLS preferences, and a vocabulary test used to estimate participants' Spanish vocabulary size. Analyses of the data suggest that a significant relationship exits between the use of certain types of learning strategies and vocabulary size among advanced, more experienced learners, but not among beginning- or intermediate-level students. Findings suggest that less experienced Spanish FL learners may be less effective at managing their own vocabulary learning. Possible reasons are addressed.
\end{abstract}

Index Terms - vocabulary learning strategies, Spanish vocabulary, vocabulary size, vocabulary learning

\section{INTRODUCTION}

Learning a second or foreign language (L2/FL) is arguably one of the most cognitively challenging undertakings most people will go through in a lifetime, and many argue that learning the vocabulary of a L2 is perhaps the most challenging aspect of becoming proficient in the target language (Meara, 1995; Milton, 2009; Nation, 2001; Schmitt, 2000). Some characteristics that distinguish vocabulary learning from other language skills include the fact that "vocabulary learning is incremental, potentially limitless, and heavily constrained by the learners' experience" (Swain \& Carroll, 1987, p. 193). One area of L2 vocabulary acquisition research that has been gaining attention in recent years to help explain the difficulties some L2 learners encounter when learning vocabulary is the focus on learning strategies-vocabulary learning strategies (VLS) in particular. Scholars' interest in L2 VLS, Schmitt (2000) argues, stems from the movement to get away from a predominantly teacher-oriented pedagogical philosophy to a more learnercentered ideology that includes an interest in how learners themselves can manage their own language learning. Schmitt believes that it may be easier to apply learning strategies to vocabulary learning due to the relatively discrete nature of vocabulary learning as compared to more integrated language skills such as reading, writing, speaking, listening, and grammar.

Learning strategies are the tools that learners use for active, self-directed language learning, and research shows that the conscious, orchestrated and tailored use of such strategies is strongly associated with language achievement and proficiency (O'Malley \& Chamot, 1990). Research on L2 learning strategies and vocabulary acquisition over the past four decades has greatly advanced our knowledge and understanding of L2 vocabulary acquisition. However, most of the L2 VLS studies conducted to date have focused on specific learning strategies under experimental conditions such as the keyword method, dictionary use and inferencing. As a result, there is a lack of research on learner-selected VLS, particularly in languages other-than-English. This study will help fill this gap by focusing on Spanish as a FL since Spanish is the fourth most common FL taught in the world (Rhodes \& Pugahl, 2009). Yet, we know relatively little about the techniques or strategies that Spanish FL students use to expand their knowledge of Spanish vocabulary and which strategies or types of strategies result in better Spanish vocabulary learning and why. After an extensive review of research studies on L2 vocabulary learning in the last decade, relatively few studies have focused on Spanish as a FL (Barcroft, 2009; Pulido, 2004, 2009; Sagarra \& Alba, 2006; Scribner, 2000). However, these studies were limited to only a handful of learning strategies such as rote memorization (Sagarra \& Alba, 2006; Scribner, 2000), semantic mapping (Sagarra \& Alba, 2006; Scribner, 2000), dictionary use (Hsien-jen, 2001), keyword mnemonics (Sagarra \& Alba, 2006; Scribner, 2000), L2 word-picture associations (Barcroft, 2009), and reading (Pulido, 2004, 2009; Pulido \& Hambrick, 2008). As a result, these studies reveal little about the self-selected vocabulary learning techniques and strategies that Spanish FL learners actually use in and out of the classroom. No study in recent decades has investigated the wide range of vocabulary learning strategies that students learning a FL actually use in and out of the classroom in order to gain vocabulary. In addition, no study has investigated the nature of the VLS FL learners resort to at different stages of language development and the effectiveness these types of strategies have on improving vocabulary development at different levels of proficiency. The present study focuses on the wide range of self-selected learning 
strategies that Spanish FL learners are using to learn Spanish vocabulary, how these strategies relate to their vocabulary proficiency, and the differences in learning strategies between learners with differing levels of language and vocabulary proficiency.

\section{BACKGROUND}

\section{A. Vocabulary Learning Strategies (VLS)}

A common belief within L2 pedagogy is the notion that some L2 learners are more successful than others. One reason may be the fact that successful learners tend to approach the task of language learning with different, sometimes more effective strategies (Anderson, 2005; Nunan, 1999). Successful FL learners know that to learn the form and meaning of a large number of FL words, to be able to store them in their memory and recall them at will, and to learn how to use them appropriately in a variety of contexts and situations, they will have to rely on wide range of learning strategies. Catalán (2003), using Oxford (1990) and Schmitt's (1997) definition for language and vocabulary learning strategies respectively, proposed the following working definition for vocabulary learning strategies in her study of VLS among FL learners:

Knowledge about the mechanisms (processes, strategies) used in order to learn vocabulary as well as steps or actions taken by students (a) to find out the meaning of unknown words, (b) to retain them in long-term memory, (c) to recall them at will, and (d) to use them in oral or written mode (p. 56).

A number of recent studies (Barcroft, 2009; Borer, 2007; Catalán, 2003; Fan, 2003; Gu, 2002; Gu \& Johnson, 1996; Schmitt, 1997; Tseng \& Schmitt, 2008) have concluded that more proficient L2 learners successfully use a variety of VLS significantly more often than less proficient students, and use learning strategies that require more cognitive effort. In fact, it has been suggested that L2 learners can be categorized on the basis of their learning strategies (Ahmed, 1989; Lawson \& Hogben, 1996). Successful L2 learners, according to Ahmed, are able to use a wider variety of cognitive demanding strategies, while less successful learners generally use fewer strategies and tend to use them inadequately. Ahmed's conclusion is an important factor to consider since research in cognitive psychology has shown that the more cognitive effort is invested in learning a word, the easier it becomes to recall that word at a later time (Baumann, Kame'enui, \& Ash, 2003; Borer, 2007; Ellis, 1995; Schmitt \& McCarthy, 1997).

Over the past thirty years, scholars have developed numerous classifications for VLS (for examples see: Cohen, 1990; Gu \& Johnson, 1996; Intaraprasert, 2004; Lawson \& Hogben, 1996; Nation, 2001; Rubin \& Thompson, 1994; Sanaoui, 1995; Schmitt, 1997; Stoffer, 1995; Winke \& Abbuhl, 2007). These classification systems have contributed substantially to the field L2 vocabulary acquisition. Schmitt (1997) developed a comprehensive and often cited taxonomy of VLS by integrating several classification systems into a taxonomy organized around Oxford's (1990) metacognitive, cognitive, memory, and social classifications of L2 learning, and Nation's (1990) distinctions between discovery and consolidation strategies (Table 1). Catalán (2003) argues that this taxonomy is popular because it offers a number of advantages not found in other taxonomies, including the fact that is comprehensive; it incorporates key elements from commonly used vocabulary learning taxonomies by Nation (1990), Oxford (1990) and Stoffer (1995), and is rooted on language learning theory as well as on theories of cognition and memory.

TABLE I

SCHMITT (1997) TAXONOMY OF L2 VOCABULARY LEARNING STRATEGIES
\begin{tabular}{|l|l|}
\hline $\begin{array}{l}\text { Discovery } \\
\text { Strategies }\end{array}$ & Determination Strategies \\
\cline { 2 - 2 } & Social Strategies \\
\hline \multirow{3}{*}{$\begin{array}{l}\text { Consolidation } \\
\text { Strategies }\end{array}$} & Social Strategies \\
\cline { 2 - 2 } & Memory Strategies \\
\cline { 2 - 2 } & Cognitive Strategies \\
\cline { 2 - 2 } & Metacognitive Strategies \\
\hline
\end{tabular}

\section{B. Cognitive Learning Strategies.}

O'Malley and Chamot (1990) describe cognitive learning strategies as those which "operate directly with incoming information" (p. 44) and the manipulation of this input to enhance learning. Cognitive learning strategies enable the L2 learner to "manipulate the language material in direct ways, e.g., through reasoning, analysis, note-taking, summarizing, synthesizing, outlining, reorganizing information to develop stronger schemas (knowledge structures), practicing in naturalistic settings, and practicing structures and sounds formally" (Oxford, 2003, p. 12).

\section{Metacognitive Learning Strategies.}

Schmitt (1997) describes metacognitive learning strategies as those "used by students to control and evaluate their own learning, by having an overview of the learning process in general" (p. 216). In other words, knowledge about learning; the techniques that L2 learners use to identify their own learning style preferences and needs, for planning L2 tasks, for gathering and organizing materials, for arranging a study space and a schedule, for monitoring mistakes and evaluating task success, and for evaluating the success of their own learning strategies (Oxford, 2003).

There are four main processes that constitute metacognitive learning: the organization of information, the management of information, the monitoring learning, and the evaluation of learning (Chamot, Keatley, Meloni, 
Gonglewski, \& Bartoshesky, 2010). Chamot, et al. (2010) argue that these metacognitive processes follow the sequential order of activities L2 learners generally go through in accomplishing any task. Planning and monitoring are generally considered two of the main processes found in most metacognitive L2 learning strategies. Monitoring processes are key to metacognitive learning since they help learners become aware of what they are doing and to bring their mental processes under conscious scrutiny and thus more effectively under control (O'Malley \& Chamot, 1990). Metacognitive learning strategies are not an automatic process, but rather the result of long-term development of cognitive processes. In the end, cognitive and metacognitive learning strategies are often used together, supporting each other (O'Malley \& Chamot, 1990).

\section{VLS and FL Proficiency.}

The main reason to investigate language learning strategies has been to determine the relationship between strategy use and L2 proficiency (Anderson, 2005). However, as Nyikos and Fan (2007) argued, few studies have considered how learning strategy preferences evolve over time and with increasing proficiency. It is believed that L2 learners with varying levels of L2 learning experience and proficiency have acquired some degree of knowledge about language learning which influences their approach to language learning and the expectations they hold about learning strategies and the outcome of their efforts (Wenden, 1998). Schmitt (1997), for example, compared three different age groups of Japanese L2 learners (junior high school students, high school students, university students and adult learners) and concluded that less experienced L2 learners rely more on mechanical learning strategies such as oral and written repetition, word lists, and flashcards than learners with higher L2 proficiency. In turn, Schmitt argues, L2 learners with higher L2 proficiency prefer more complex metacognitive strategies such as the use of dictionaries, guessing from context, imaging word meanings, asking teachers for paraphrases or synonyms, word part analysis, and connecting words with personal experiences. Regardless of L2 developmental stage, Nyikos \& Fan (2007) argued, results from study after study indicate that successful L2 learners, for the most part, show a pattern of selecting more complex, appropriate, and task-compatible strategies for learning new L2 words and achieve results comparable to more proficient L2 learners. In fact, Anderson (2005) argues that language proficiency level can explain between .30 and .78 of the variance in learning strategy use.

The evidence reviewed so far suggests that VLS used by FL learners may vary depending on the learners' language proficiency and experience with the target language. Thus, the focus of the present study is to evaluate the use of different types of self-selected learning strategies at different levels of Spanish FL proficiency and their relationship to Spanish vocabulary size.

\section{RESEARCH QUESTIONS}

1. What is the relationship between VLS used by adult Spanish FL students at different levels of proficiency and their vocabulary size?

2. Do beginner, intermediate and advanced adult Spanish FL learners differ significantly in the types of VLS they report using? If so, what are the main patterns of variation?

3. What type of VLS are associated with higher vocabulary gains within different proficiency levels and why?

\section{METHODOLOGY}

\section{A. Setting and Participants.}

The present study took place at a U.S. military undergraduate academic institution during the fall semester of 2010. This institution of higher learning is a fully accredited undergraduate academic institution with an approximate enrollment of 4,400 students. FL courses at this institution are divided into three levels: 100-level courses designed for beginner-level basic FL skill development, 200-level courses designed for intermediate-level basic FL skill development, and 300-level courses which focus primarily on FL conversational skills for advanced level FL students. The participants in this research study included 475 students enrolled in Spanish FL courses at the 100-level $(\mathrm{n}=182)$, 200-level $(\mathrm{n}=188)$, and 300-level $(\mathrm{n}=105)$. Each student at this academic institution is placed in the appropriate FL course level based on prior experience with the FL and the results from a placement test they are given prior to the start of their freshman year. In addition, during the first four weeks of instruction, FL instructors and professors are tasked with reevaluating the proficiency level of each student and, if necessary, transferring the student to the appropriate proficiency level course. As is common at military academic institutions, $80 \%$ of participants were male students and $20 \%$ were female. All participants were between the ages of 18 and 24 .

\section{B. Instruments.}

Two instruments were used in this Spanish FL VLS study: a Spanish L2 vocabulary learning questionnaire (VLQ) with a demographics survey and a Spanish Yes-No Vocabulary Checklist Test. The participants were also given two Scantron sheets to record their answers - one for the demographic survey and VLQ, and another for the vocabulary test. The two Scantron sheets that each participant received were pre-marked with a three-digit number in order to match the two forms and merge the answers each student gave in each of the two assessment instruments. 
Spanish Vocabulary Learning Questionnaire (VLQ). Schmitt's VLS taxonomy (1997) incorporates 59 different strategies divided into two domains: strategies used to infer the meaning of the unknown words (discovery strategies), and strategies used to consolidate the meaning of the new word (consolidation strategies). Schmitt's taxonomy includes commonly used VLS which fall in one of the following six categories: 1) Discovery-determination (e.g. analyzing parts of speech, checking for L1 cognates, guessing from context, and use of bilingual or monolingual dictionary), 2) Discovery-social (e.g. asking the L2 teacher for an L1 translation, asking classmates for meaning, and discovering meaning through a group work activity), 3) Consolidation-social (e.g. study and practice word meaning in a group and interaction with native speakers), 4) Consolidation-memory (e.g. study word with a pictorial representation of its meaning, using semantic maps, imaging word form, using keyword mnemonics, and connecting words to a personal experience), (5) Consolidation-cognitive (e.g. note-taking, verbal repetition, written repetition, word lists, flash cards, and keeping a vocabulary journal or notebook), and 6) Consolidation-metacognitive (e.g. testing oneself with word tests, use of target language media, using spaced word practice and continuing to study a word over time).

The Spanish VLQ that was used for this study was adapted from Catalán's study (2003) which used Schmitt's (1997) taxonomy of L2 vocabulary learning. Schmitt's VLS taxonomy is divided into two domains based on Nation's (1990) suggestions: discovery strategies (items 1 through 14), which are strategies used to discover the meaning of an unknown word, and consolidation strategies (items 15 through 60), which are strategies used to consolidate (i.e. learn) the meaning of a previously unknown word. Discovery strategies are further subdivided into determination strategies (items 1 through 9) and social strategies (items 10 through 14). Consolidation strategies, on the other hand, are subdivided into social (items 15 through 17), memory (items 18 through 44), cognitive (items 45 through 53), and metacognitive strategies (items 54 through 60). In addition, after a pilot study in which 14 university students enrolled in FL courses were asked to add any additional vocabulary learning strategies they used and that were not listed in Schmitt's taxonomy, it was decided to add two items to the questionnaire: 1) an item on computer-based VLS (item No. 59), which were not common when this taxonomy was created in the mid-90s but is extensively used at this institution and most other schools today, and 2) extensive FL reading (item No. 60), which was a common strategy among the participants in the pilot study and an effective and commonly used strategy for vocabulary learning. Using Schmitt's (1997) definition of metacognitive learning strategies, both of these items were added to the metacognitive section of the taxonomy. Using a scantron sheet to record their answers, students had to respond to whether they use each strategy A (never), B (infrequently), C (sometimes), D (often) and E (very often) using a 5-point Likert scale. Each answer was worth between one point (A) and five points (E). Option A was worth 1 point; option B was worth 2 points, and so forth. Averages were computed for each strategy in each proficiency group.

Participants were asked to answer the VLQ anonymously. No personal identifiable information was asked of any participant in order to counteract the tendency for respondents to answer what they perceive to be the right answer in the researcher's mind. Section I of the VLQ was developed in order to ascertain general demographic information of each participant. Participants were asked to fill out the multiple choice demographic survey using a scantron sheet. In order to answer research question two, strategies that received an average score of 3.0 or above-strategies used sometimes (3), often (4) or very often (5) - were considered as the strategies normally used by students. In their studies on VLS, Schmitt (1997) and Catalán (2003) did not use a Likert scale for their questionnaires. Instead, they asked their participants to mark whether or not they use each of the strategies on the questionnaire; whether they use them sometimes, often or very often. Therefore, for the present study 3.0 and above was the average threshold of use for each strategy.

Spanish Yes-No Vocabulary Checklist Test. The Yes-No Vocabulary Checklist Test was adapted from Meara and Milton's (2003) Yes-No lexical frequency based test of vocabulary size. This test was designed to measure students' passive recognition of Spanish words in a list of relatively high frequency Spanish words (Davies, 2006). The vocabulary proficiency scores from this test were used as the dependent variable that represents students' most basic knowledge of a word - the passive recognition of a Spanish word. In a study of vocabulary knowledge hierarchies, Laufer and Goldstein (2004) were able to find a significant Pearson correlation of .49 ( $p<.001)$ between scores on a passive recognition vocabulary test and the participants L2 class grade point average.

The Yes-No Vocabulary Size Test was originally developed in the mid-eighties by Meara and Buxton (1987) with a simple checklist format in which test-takers are required to indicate whether they know a target word by checking a yes or no box next to each word. The checklist format allows for a large number of vocabulary items to be tested and scored in a limited amount of time.

The Yes-No test consists of two different types of words: real words and pseudo or fake words. Pseudowords are words that fulfill the phonological and orthographical constraints of the target language but do not bear any meaning (Alderson, 2005; Mochida \& Harrington, 2006). These pseudowords provide a basis for adjusting the scores of those students who tend to overestimate their vocabulary knowledge. A 'yes' response to a real word is labeled as a hit, while a 'no' response is labeled a miss. On the other hand, a 'yes' response to a pseudoword is labeled a false alarm, while a 'no' response to a pseudoword is labeled as a correct rejection (Table 2). Test-takers know that the test contains pseudowords but they do not know how many nor their location on the test, which gives them little choice but to be honest with their responses. 
TABLE II.

YES-NO VOCABULARY CHECKLIST TEST SIMPLE TOTAL SCORING

\begin{tabular}{|l|l|l|}
\hline Know it? & Yes & No \\
\hline Real Word & HIT & MISS \\
\hline Pseudoword & FALSE ALARM & CORRECT REJECTION \\
\hline
\end{tabular}

The Spanish Yes-No vocabulary test used in the present study included 100 Spanish content words and 50 pseudowords in randomized order. Only Spanish verbs were used since in most languages there are relatively fewer verbs than other lexical forms; nouns are a large category and adjectives are often derived from nouns (Alderson, 2005). The 100 Spanish verbs were randomly selected from the 1074 verbs found in the 5000 most-frequently-used Spanish words list (Davies, 2006). The 100 word list includes a representative sample from each of Davies' five Spanish vocabulary frequency bands: 1000, 2000, 3000, 4000 and 5000 levels. According to Davies and Face (2006), the 5000 most-frequently-used Spanish words cover 98 percent of the words found in authentic texts and represent the core of vocabulary knowledge that Spanish native speakers acquire early in life. Therefore, a representative sample of the 1074 Spanish verbs in the 5000 word list should yield a reasonable estimate of overall Spanish vocabulary size. Participants were given a separate scantron sheet to respond to the multiple choice vocabulary test and were instructed to select " $\mathrm{A}$ " on their scantron sheets if they knew the word's most basic meaning or "B" if they did not. They were also instructed not to guess, since guessing is easily detected by the use of fake words.

Vocabulary Test Scoring. There are several different procedures that have been proposed for scoring the Yes-No vocabulary checklist test and some disagreements prevail as to which scoring system results in the most valid and reliable scores (Beeckmans, Eyckmans, Janssens, Dufranne, \& Van de Velde, 2001; Huibregtse, Admiraal, \& Meara, 2002; Mochida \& Harrington, 2006). However, according to developers of the European Union's Diagnostic Language Test-DIALANG (Alderson, 2005), the most accurate and reliable scoring method is the simple total (also known as raw hits), which represents the total number of categorical hits and correct rejections- that is, 'yes' responses to real words and 'no' responses to pseudowords. Therefore, for the present study, the simple total scoring method was used to estimate each participant's Spanish vocabulary size. The scores test-takers earned in the Yes-No vocabulary test, therefore, range from zero points (lowest vocabulary size) to 150 points (highest vocabulary size) according to the number of hits and correct rejections each test-taker achieved on the vocabulary test.

The two Scantron sheets that each participant used were scanned by a Scantron reader and downloaded into Excel spreadsheets. Two Excel spreadsheets were created, one with all the participants' answers to the demographic questions and the VLQ, and another with the participants' answers to the vocabulary test. Once the scores to the vocabulary test were obtained for each participant, they were manually inserted in the VLQ spreadsheet as an additional column ensuring that each score was attributed to the right participant by means of identification numbers. Once all the answers and scores for each participant were recorded, they were divided into three separate spreadsheets - one each for beginning, intermediate, and advanced groups. The next step was to obtain an average score for each of Schmitt's six categories of VLS. The average scores per rows (participants) and per columns (strategies) were calculated. The average VLS scores for each participant within each proficiency level, plus their corresponding vocabulary test scores were then recorded in each spreadsheet by adding additional columns.

\section{Data ANALYSis}

First, an ANOVA was performed on the vocabulary test scores to determine how much of the total variability among scores can be attributed to the participants' language proficiency group. Then, multiple linear regression analyses were conducted on the results from each proficiency group in order to obtain answers to our first research question; the vocabulary test scores represented the dependent variable in the regression analysis, while the number of study hours per week and the average score for each of the six learning strategy categories represented the independent variables. In order to answer research question two, it was necessary to determined first which learning strategies in the VLQ received an overall average score of 3.0 and above (strategies used sometimes, often, and very often) within each proficiency group in order to make comparisons between each group. An ANOVA test was also performed to determine whether any significant differences exist in the study habits between the three groups in this study.

\section{RESULTS}

\section{A. Spanish Yes-no Vocabulary Size Test Results.}

The average vocabulary test score for all participants was 84.17 out of 150 possible points, with a range of 51 to 143 . The beginning group had an average score of 72.66 , the intermediate group averaged 83.32, and the advanced group averaged 105.75 points (see Table 3). The vocabulary test's Cronbach's Alpha internal reliability coefficient was 967 which suggests highly reliable results. In addition, a one-way ANOVA showed that there was a significant difference in the vocabulary test score means between the three Spanish proficiency groups: $\mathrm{F}(2,478)=186.07, p<.001$. Furthermore, the R-Squared value of .439 revealed that 43.9 percent of the variance in the vocabulary test scores can be attributed to the participants' language proficiency group placement. Furthermore, a multiple comparisons Scheffe Post Hoc Test revealed that the vocabulary size test score means from all three Spanish FL proficiency groups differed 
significantly from each other $(p<.001)$. In addition, the vocabulary test means for the three proficiency groups of Spanish FL students shows a clear and predictable pattern of vocabulary knowledge increase from beginning level through intermediate and advanced levels.

TABLE III.

VoCABULARY TEST RESUlTS DESCRIPTIVE STATISTICS

\begin{tabular}{lccllll}
\multicolumn{7}{c}{ VOCABULARY TEST RESULTS DESCRIPTIVE STATISTICS } \\
\hline Proficiency & $\mathrm{N}$ & Mean & $\begin{array}{l}\text { Std. } \\
\text { Deviation }\end{array}$ & $\begin{array}{l}\text { Std. } \\
\text { Error }\end{array}$ & Minimum & \multirow{2}{*}{ Maximum } \\
\hline Beginners & 183 & 72.66 & 12.52 & .92 & 51.00 & 117.00 \\
Intermediates & 187 & 83.32 & 13.34 & .97 & 54.00 & 116.00 \\
Advanced & 105 & 105.75 & 15.40 & 1.50 & 57.00 & 143.00 \\
Total & 475 & 84.17 & 18.34 & .84 & 51.00 & 143.00 \\
\hline
\end{tabular}

The Yes-No Spanish Vocabulary Size Test included words from five Spanish word frequency band levels (1000-, 2000-, 3000-, 4000-, and 5000-level words) and 50 pseudowords. Table 4 below presents the breakdown of the vocabulary test scores by language proficiency and word frequency levels. Participants from all three proficiency groups achieved almost the same mean of correct rejections for pseudowords, suggesting that performance on pseudowords in the Yes-No vocabulary checklist test does not distinguish between proficiency levels. Finally, according to the results from an ANOVA test of between levels effects, the vocabulary size test scores from each word frequency level differ significantly from each other $(p<.001)$ except for pseudowords.

TABLE IV.

HITS AND CORRECT REJECTIONS BY PROFICIENCY GROUP AND WORD FREQUENCY LEVELS

\begin{tabular}{llll}
\hline $\begin{array}{l}\text { Word Frequency } \\
\text { Level }\end{array}$ & \multicolumn{3}{l}{ Percentage of Hits and Correct Rejections by Proficiency Group } \\
\hline & Beginning (\%) & Intermediate (\%) & Advanced (\%) \\
1000-Level & 44.96 & 61.61 & 84.36 \\
2000-Level & 24.57 & 37.83 & 69.17 \\
3000-Level & 29.74 & 35.42 & 54.42 \\
4000-Level & 19.05 & 27.55 & 43.25 \\
5000-Level & 8.6 & 9.6 & 29.0 \\
Pseudowords & 87.06 & 86.96 & 87.94 \\
\hline
\end{tabular}

\section{B. Vocabulary Learning Questionnaire (VLQ) Results}

In order to determine the reliability of the responses to the 60-item VLQ, an internal reliability test was conducted. The result was a Cronbach's Alpha internal reliability coefficient of .901. The participants' responses to the VLQ suggest a slight increase in the number of VLS used by students as they progress from beginning-level (19 VLS) through intermediate (24 VLS) and advanced-level (25 VLS) FL courses. Almost half of the 31 strategies that participants claimed to use (14 out of 31) were used by participants in all three groups, which suggests that many of these VLS are popular among Spanish FL students regardless of proficiency level. The advanced group, however, had a larger number of unique learning strategies not used by neither beginning nor intermediate groups.

Multiple linear regression analyses were conducted within each group of Spanish FL learners to examine the linear correlations between the independent variables (six types of VLS) and the dependent variable (vocabulary size score). On average, beginning-level students achieved a mean score of 73.1 on the dependent variable - the vocabulary size test. Among the six independent variables under assessment, determination strategies received the highest mean score (3.15) and consolidation social strategies received the lowest (2.2). According to the ANOVA results (Table 5), however, the relationship between the predictive variables and the dependant variable in the beginning-level group was found to be not significant $(\mathrm{F}=.883, p<.52)$. Thus, these results suggest that there is no significant relationship between the type of VLS participants in the beginning group report using, as proposed by Schmitt (1997), and their vocabulary size test scores.

TABLE V.

BEGINNING GROUP ANALYSIS OF VARIANCE

\begin{tabular}{llllll}
\multicolumn{7}{c}{ BEGINNING GrouP ANALYSIS OF VARIANCE } \\
\hline Model & Sum of Squares & df & Mean Square & F & Sig. \\
\hline $1 \quad$ Regression & 1018.180 & 7 & 145.454 & .883 & $.521^{\text {a }}$ \\
& 28992.858 & 176 & 164.732 & & \\
Residual & 30011.038 & 183 & & & \\
\multicolumn{1}{c}{ Total } & Strategies, Cognitive Strategies, Memory Strategies, and Metacognitive Strategies \\
\hline a. Predictors: Determination Strategies, Consolidation Social Strategies, Discovery Social \\
b. Dependent Variable: Vocabulary Score
\end{tabular}

The intermediate-level Spanish FL students achieved a mean score of 84.43 on the dependent variable-the vocabulary size test. Among the six independent variables under assessment, again determination strategies received the highest mean score (3.18) and again consolidation social strategies received the lowest (2.27). According to the 
ANOVA results (Table 6), however, the relationship between the predictive variables and the dependant variable in the intermediate-level group was also found to be not significant $(\mathrm{F}=.959, p<.463)$. Again, these results suggest that there is no significant relationship between the type of VLS participants in the intermediate group report using.

TABLE VI.

INTERMEDIATE GROUP ANALYSIS OF VARIANCE

\begin{tabular}{lllllll}
\hline \multicolumn{1}{l}{ Model } & & Sum of Squares & df & Mean Square & F & Sig. \\
\hline 1 & Regression & 1298.192 & 7 & 185.456 & .959 & $.463^{\mathrm{a}}$ \\
& Residual & 34823.909 & 180 & 193.466 & & \\
& Total & 36122.101 & 187 & & \\
\hline
\end{tabular}

a. Predictors: Memory Strategies, Discovery Social Strategies, Cognitive Strategies, Consolidation Social Strategies, Metacognitive Strategies, Determination Strategies

b. Dependent Variable: Vocabulary Test Score

Finally, the advanced-level students achieved a mean score of 105.75 on the dependent variable - the vocabulary size test. Among the six independent variables under assessment, again determination strategies received the highest mean score (3.07) and, as with the two other groups, consolidation social strategies received the lowest (2.15). Unlike the previous two groups, however, the ANOVA results for the participants in the advanced group (Table 7) reveal that there is a significant relationship between at least one independent variable and the dependent variable - vocabulary size $(\mathrm{F}=$ $4.1, p<.001)$.

TABLE VII

ADVANCED GROUP ANALYSIS OF VARIANCE

\begin{tabular}{lllllll}
\hline \multicolumn{1}{l}{ Model } & Sum of Squares & df & Mean Square & F & Sig. \\
\hline 1 & Regression & 5643.526 & 7 & 806.218 & 4.108 & $.001^{\mathrm{a}}$ \\
& Residual & 19036.036 & 97 & 196.248 & & \\
& Total & 24679.562 & 104 & & & \\
\hline
\end{tabular}

a. Predictors: Memory Strategies, Discovery Social Strategies, Cognitive Strategies, Consolidation Social Strategies, Metacognitive Strategies, Determination Strategies

b. Dependent Variable: Vocabulary Test Score

To determine which of the six independent variables under assessment can significantly predict the outcome on the dependent variable, Table 8 represents the variance breakdown for each of the independent variables. These results show that only three independent variables can significantly predict the outcome on the dependent variable within the advanced group: Consolidation Social $(p<.004)$, Cognitive $(p<.002)$ and Metacognitive $(p<.02)$ learning strategies.

TABLE VIII.

ADVANCED GROUP BREAKDOWN OF VARIANCE FOR EACH INDEPENDENT VARIABLE

\begin{tabular}{|c|c|c|c|c|c|c|}
\hline & & \multicolumn{2}{|c|}{ Unstandardized Coefficients } & \multirow{2}{*}{$\begin{array}{l}\text { Standardized Coefficients } \\
\text { Beta }\end{array}$} & \multirow[b]{2}{*}{$\mathrm{t}$} & \multirow[b]{2}{*}{ Sig. } \\
\hline \multicolumn{2}{|c|}{ Model } & B & Std. Error & & & \\
\hline \multirow[t]{7}{*}{1} & (Constant) & 105.965 & 12.015 & & 8.820 & .000 \\
\hline & Determination Strategies & -1.445 & 4.215 & -.037 & -.343 & .732 \\
\hline & Discovery Social Strategies & -3.143 & 2.814 & -.130 & -1.117 & .267 \\
\hline & Consolidation Social Strategies & 7.389 & 2.509 & .324 & 2.945 & .004 \\
\hline & Memory Strategies & -1.802 & 4.347 & -.053 & -.414 & .679 \\
\hline & Cognitive Strategies & -7.570 & 2.434 & -.318 & -3.111 & .002 \\
\hline & Metacognitive Strategies & 7.315 & 3.271 & .255 & 2.236 & .028 \\
\hline
\end{tabular}

In order to determine the strength of this relationship, the model's R-Square value was calculated. The model summary reveals that 23 percent of the variance (R-Square .229) in the dependent variable (vocabulary test scores) can be attributed to the use of Consolidation Social, Cognitive and Metacognitive learning strategies. Thus, from these results it can be inferred that the use of Consolidation Social, Cognitive and Metacognitive learning strategies, as proposed by Schmitt (1997), can significantly predict up to 23 percent of the variance in the scores on the vocabulary size test among the participants in the advanced-level group $(\mathrm{F}=4.1, p<.001)$.

\section{DISCUSSION}

The results from the VLQ point to a slight increase in the number of VLS used by students as they progress from beginning (19 VLS) through intermediate (24 VLS) and advanced (25 VLS) Spanish FL proficiency levels. The literature on L2 VLS suggest that more proficient L2 learners successfully use a variety of VLS significantly more often and with more efficiency than inexperienced, less proficient L2 learners (e.g. Barcroft, 2009; Borer, 2007; Catalán, 
2003; Ehrman \& Oxford, 1995; Fan, 2003; Gu, 2002; Schmitt, 1997; Tseng \& Schmitt, 2008). Furthermore, there is a strong relationship between strategy use and L2 proficiency. According to research, proficiency level can explain between .30 and .78 of the variance in strategy use (Anderson, 2005). The results from the present study support these previous findings; experienced FL students tend to use more strategies for learning vocabulary than novice learners. Among both beginner- and intermediate-level students, there was a lack of significant correlations between the independent variables and the vocabulary test results. This lack of relationships between VLS and vocabulary size among less experienced Spanish FL learners, although somewhat unexpected, is not surprising. Based on these results, it could be inferred that the VLS that beginning and intermediate Spanish FL students report using have little to no effect on their vocabulary size. There are several plausible explanations for this finding. One possibility, the literature suggests, is the theory that language learning strategies are higher-order cognitive and metacognitive processes that require additional cognitive skills or resources that less-proficient or less-experienced L2 learners may not have at their disposal (e.g. Ellis, 1995; Laufer, 1997; O'Malley \& Chamot, 1990; Pulido, 2004, 2009). Research findings suggest that using language learning strategies may not ensure success in language learning, especially if learners do not have the knowledge and experience to be able to metacognitively connect their learning strategies and their language use (Vann \& Abraham, 1990). The demographic survey in this study revealed that, on average, participants in both the beginning and the intermediate groups had studied Spanish for less than two years and only three percent had studied a language other than Spanish or their L1. This information reveals the participants in these two groups are in fact inexperienced FL learners who may have not yet developed the advanced metacognitive learning skills to manage their FL vocabulary learning more effectively. According to some studies (e.g. Ellis, 2002; Pulido, 2009), less-proficient language learners use their available cognitive resources and skills for lower-level linguistic processes and have fewer resources available to effectively monitor and evaluate their learning through the use of more sophisticated metacognitive language learning strategies. Research on L2 learning strategies consistently shows that inexperienced and less successful L2 learners use the same learning strategies repeatedly even if they make no significant progress in their tasks (Anderson, 2005). Furthermore, similar research findings (e.g. Nassaji, 2003, 2004; Nation, 1997; Prince, 1996; Qian, 2002) also reveal that novice L2 learners lack the basic L2 vocabulary foundation necessary to take advantage of more sophisticated language learning strategies such as inferencing from context, extensive L2 reading, social interaction with target language speakers, and other deeper-processing (Ellis, 2002) learning strategies used by more proficient L2 learners. According to the vocabulary size test, the beginning group in this study had receptive (or higher) knowledge of only 34 percent of the 2000 most-frequently-used Spanish words (45 percent of 1000-level words and 24.5 percent of 2000 level words) while the intermediate group had receptive (or higher) knowledge of 49 percent of the 2000 mostfrequently-used Spanish words (61.6 percent of 1000-level words and 37.8 percent of 2000-level words) (see Table 2). Thus, the evidence suggests that inexperienced L2 learners may have to resort to popular memorization strategies in order to build that basic vocabulary foundation necessary to engage in more cognitively-demanding learning strategies (Meara, 1995, 1996).

Yet another plausible explanation is related to other learner-dependent and external factors influencing their learning. The SLA literature informs us that there are many factors that can influence L2 learning other than target language proficiency and learning strategies, particularly at the beginning stages of L2 acquisition and development (Gass \& Selinker, 2008). These factors may include the learning environment; FL versus L2, gender, motivation, anxiety, beliefs about L2 learning, the learning tasks, and learners' cultural background. All these factors are relatively stable and can determine to an extent how a language learner approaches vocabulary learning (Gu, 2003). Thus, since most FL students at schools around the U.S. do not receive explicit instruction on FL vocabulary learning strategies (Beck, McKeown, \& Kucan, 2002; Folse, 2004; Schmitt, 2000), it may be possible that the less-experienced FL learners in this study have never been taught or have not fully developed effective language learning strategies and techniques that may enhance their learning efficiency and vocabulary gains. Instead, other learner-dependent and external factors (such as the ones mentioned above) may be playing a more significant role in their vocabulary development than the learning strategies they use. Future studies should examine how much instruction learners have received on VLS in order to analyze their effectiveness. These findings also highlight the positive influence that explicit training on effective cognitive and metacognitive learning strategies can have on inexperienced or novice FL learners.

In order to determine whether differences in VLS preferences exist between participants with high and low vocabulary size test scores (research question three), the VLS used by students in the top one third of vocabulary test scores in each group were compared with those in the bottom one third. The results, however, show no significant differences in the patterns of VLS used between high- and low-scoring participants in the beginning or intermediate groups. Again, suggesting perhaps that less-experienced FL learners lack the metacognitive knowledge to manage their vocabulary development more effectively.

Perhaps the most interesting and significant findings in this study were among the participants in the advanced proficiency group. Results from this group suggest that advanced-level FL students have acquired a larger repertoire of VLS than beginning- and intermediate-level FL students. The demographic survey reveals that the participants in the advanced group had studied Spanish for an average of five years prior to this study. This may suggest that the strategic learning habits of more experienced FL learners are more effective in overcoming the negative effects that other external and learner-dependent factors may have on FL vocabulary acquisition. In addition, Pearson correlation 
analyses showed that significant differences in VLS use exist even with participants within this advanced group - those with high vocabulary scores differed in the VLS they claimed to use from those with low vocabulary test scores. These findings revealed an interesting trend, both sets of participants within the advanced group, those with the highest and the lowest vocabulary test scores, report using the same number of VLS (21). However, six of the 21 VLS used by advanced students were unique to the high-scoring group while five were unique to the low-scoring group. Those with low vocabulary scores relied more on memorization and cognitive strategies while those with higher vocabulary test scores relied more on social and metacognitive strategies. This finding supports Ellis' (1995) conclusions that experienced and successful language learners "use sophisticated metacognitive knowledge to choose suitable cognitive learning strategies appropriate to the task of vocabulary acquisition" (p. 117). Among the low-scoring group, four of their five unique VLS had significant negative correlations with their vocabulary test scores: grouping words together ($.228)$, using the keyword method (-.253), creating wordlists with L1 translations (-.306), and memorizing the vocabulary section of their textbooks (-.211). In contrast, three of the six VLS unique to the high-scoring group had significant positive correlations with their vocabulary test scores: using the word in interactions with Spanish speakers (.353), listening/watching Spanish media-music, videos, TV, film (.416), and reading Spanish texts (.297). These results suggest that, among advanced, more experienced FL learners, social and metacognitive learning strategies may be more effective at improving vocabulary gains, while learners that rely heavily on memorization techniques such as the keyword method and the use of wordlists may not be as effective at learning vocabulary. Again, one must be cautious not to infer a cause and effect relationship based on these correlations. This study does not provide empirical evidence to imply that the use of these strategies significantly improves or deteriorates vocabulary knowledge. Merely, it points to the fact that there are significant positive and negative correlations between the use of certain learning strategies and vocabulary size test scores among advance Spanish FL learners.

Research suggests that memorization strategies are common and popular among L2 learners (Fitzpatrick, Al-Qarni, \& Meara, 2008; Folse, 2004; Milton, 2009; Read, 2000). Many researchers in the field of SLA (Fitzpatrick, et al., 2008; Lawson \& Hogben, 1996; Meara, 1995; Pulido, 2009; Schmitt, 2000) believe that at lower proficiency levels, learners using memorization techniques will have better results, whereas more advanced learners will benefit more from the context found in more cognitively-demanding tasks. However, previous studies with Spanish FL learners (including the present study) have shown that the use of memorization strategies for vocabulary learning are less effective strategies among Spanish FL vocabulary learners (Barcroft, 2009; Sagarra \& Alba, 2006; Scribner, 2000). Sagarra and Alba (2006), for example, found that the Spanish FL students in their study who used more involved metacognitive learning strategies improved significantly more than those who relied on rote repetition and other memorization techniques. Scribner (2000) also concluded that rote memorization was the least effective learning method for all three Spanish FL proficiency groups in her study. Most recently, Barcroft (2009) also found that the lowest proficiency scores in his study were attained by Spanish FL learners who used L2-L1 translation and repetition techniques. Thus, the negative results from the use of memorization strategies among advanced learners in previous studies, as well as results from the present study, may suggest that memorization strategies may arguably be better suited for beginning-level FL learners who are in the initial receptive knowledge-building stage of vocabulary growth, and not for more experienced and proficient FL learners who may benefit more from cognitively-demanding social and metacognitive strategies that promote long-term productive knowledge of vocabulary.

\section{CONCLUSION}

The results from this research study add to the body of literature related to the use of VLS in FL vocabulary learning. It is clear that for most FL students, learning vocabulary is the most common activity in the language learning process and perhaps the most frustrating one as well. There is little doubt that FL learners want to have greater control over their own vocabulary development. Unfortunately, inexperienced language learners are not always aware of the benefits of conscious and continuous use of effective learning strategies for making learning quicker and more effective, and many FL teachers are not savvy on language and vocabulary learning strategy instruction and/or techniques at different levels of proficiency. FL VLS research, however, is still in its infancy, and as Oxford (2003) pointed out, the categorization of learning strategies is still fluid and open to debate.

Findings from the present study support the argument that novice Spanish FL learners may lack the metacognitive knowledge, skills and experience to better manage their vocabulary learning. Future research should continue to evaluate the effectiveness of explicit instruction on the use of learning strategies and its effect on FL vocabulary acquisition. Perhaps future research will also result in a more standardized and valid model for FL VLS which takes into account language proficiency, experience and metacognitive knowledge of language learning.

\section{REFERENCES}

[1] Ahmed, M. (1989). Vocabulary learning strategies. In P. Meara (Ed.), British studies in applied linguistics: Vol. 4. Beyond words (pp. 3-14). London: British Association of Applied Linguistics/Center for Language Teaching.

[2] Alderson, J. (2005). Diagnosing foreign language proficiency: The interface between learning and assessment. New York: Continuum. 
[3] Anderson, N. (2005). L2 strategy research. In E. Hinkel (Ed.), Handbook of research in second language teaching and learning (pp. 757-772). Mahwah, NJ: Lawrence Erlbaum Associates.

[4] Barcroft, J. (2009). Strategies and performance in intentional L2 vocabulary learning. Language Awareness, 18(1), 74-89.

[5] Baumann, J., Kame'enui, E., \& Ash, G. (2003). Handbook of research on teaching the English language arts. In J. Flood, D. Lapp, J. Squire \& J. Jensen (Eds.), Research on vocabulary instruction: Voltaire redux (2nd ed., pp. 1128): Lawrence Erlbaum.

[6] Beck, I., McKeown, M., \& Kucan, L. (2002). Bringing words to life: Robust vocabulary instruction. New York, NY: The Guilford Press.

[7] Beeckmans, R., Eyckmans, J., Janssens, V., Dufranne, M., \& Van de Velde, H. (2001). Examining the Yes/No vocabulary test: some methodological issues in theory and practice. Language Testing, 18(3), 235-274.

[8] Borer, L. (2007). Depth of processing in private and social speech: Its role in the retention of word knowledge by adult EAP learners. Canadian Modern Language Review, 64(2), 269-295.

[9] Catalán, R. (2003). Sex differences in L2 vocabulary learning strategies. International Journal of Applied Linguistics, 13(1), 54-77.

[10] Chamot, A., Keatley, C., Meloni, C., Gonglewski, M., \& Bartoshesky, A. (2010). Developing Autonomy in Language Learners. In C. f. A. Linguistics (Ed.). Washington, DC: National Capital Language Resource Center.

[11] Cohen, A. (1990). Language learning: Insight for learners, teachers, and researchers. Boston: Heinle \& Heinle.

[12] Davies, M. (2006). A frequency dictionary of Spanish: Core vocabulary for learners. New York: Routledge

[13] Davies, M., \& Face, T. (2006). Vocabulary coverage in Spanish textbooks: How representative is it? Paper presented at the 9th Hispanic Linguistics Symposium, Somerville, MA.

[14] Ehrman, M., \& Oxford, R. (1995). Cognition plus: Correlates of language learning success. The Modern Language Journal, 79 , 67-89.

[15] Ellis, N. (1995). The psychology of foreign language vocabulary acquisition: Implications for CALL. Computer Assisted Language Learning, 8(2-3), 103-128.

[16] Ellis, N. (2002). Frequency effects in language processing: A review with implications for theories of implicit and explicit language acquisition. Studies in Second Language Acquisition, 24, 143-188.

[17] Fan, M. (2003). Frequency of use, perceived usefulness, and actual usefulness of second language vocabulary strategies: A study of Hong Kong learners. Modern Language Journal, 87(2), 222-241.

[18] Fitzpatrick, T., Al-Qarni, I., \& Meara, P. (2008). Intensive vocabulary learning: A case study. Language Learning Journal, $36(2), 239-248$

[19] Folse, K. (2004). Vocabulary myths: Applying second language research to classroom teaching. Ann Arbor, MI: Michigan Press.

[20] Gass, S., \& Selinker, L. (2008). Second language acquisition: An introductory course (3rd ed.). New York, NY: Routledge.

[21] Gu, Y. (2002). Gender, academic major, and vocabulary learning strategies of Chinese EFL learners. Regional English Language Centre Journal, 33(1), 35.

[22] Gu, Y. (2003). Vocabulary learning in a second language: Person, task, context and strategies. Teaching English as a Second or Foreign Language-Electronic Journal, 7(2). Retrieved July, 2010 from http://www.tesl-ej.org/wordpress/pastssues/volume7/ej26/ej26a4/

[23] Gu, Y., \& Johnson, R. (1996). Vocabulary learning strategies and language learning outcomes. Language Learning, 46(4), 643679.

[24] Hsien-jen, C. (2001). The effects of dictionary use on the vocabulary learning strategies used by language learners of Spanish. Paper presented at the Annual Meeting of the Acquisition of Spanish and Portuguese as First and Second Languages. Retrieved May, 2010 from http://ezproxy.lib.utexas.edu/login?url=http://search.ebscohost.com/login.aspx?direct=true\&db=eric\&AN=ED 471315\&site=ehost-live

[25] Huibregtse, I., Admiraal, W., \& Meara, P. (2002). Scores on a yes-no vocabulary test: Correction for guessing and response style. Language Testing, 19(3), 227-245.

[26] Intaraprasert, C. (2004). EST students and vocabulary learning strategies: A preliminary investigation (Research Study). Nakhon Ratchasima, Thailand: Suranaree University of Technology.

[27] Kojic-Sabo, I., \& Lightbown, P. (1999). Students' approaches to vocabulary learning and their relationship to success. Modern Language Journal, 83(2), 176-192.

[28] Laufer, B. (1997). The lexical plight in second language reading: Words you don't know, words you think you know and words you can't guess. In J. Coady \& T. Huckin (Eds.), Second language vocabulary acquisition: A rationale for pedagogy (pp. 20 34). New York, NY: Cambridge University Press.

[29] Laufer, B., \& Goldstein, Z. (2004). Testing vocabulary knowledge: Size, strength, and computer adaptiveness. Language Learning, 54(3), 399-436.

[30] Lawson, M., \& Hogben, D. (1996). The vocabulary-learning strategies of foreign-language students. Language Learning, 46(1), $101-135$.

[31] Meara, P. (1995). The importance of an early emphasis on L2 vocabulary. JALT, 19, 8-11. Retrieved February, 2010 from http://www.jalt-publications.org/tlt/files/95/feb/meara.html

[32] Meara, P. (1996). The vocabulary knowledge framework. _lognostics: tools for vocabulary researchers. Retrieved September, 2010, from http://www.lognostics.co.uk/vlibrary/meara1996c.pdf

[33] Meara, P., \& Buxton, B. (1987). An alternative to multiple choice vocabulary tests. Language Testing, 4(2).

[34] Meara, P., \& Milton, J. (2003). X_Lex, the Swansea Vocabulary Levels Test: Newbury: Express Publishing.

[35] Milton, J. (2009). Measuring second language vocabulary acquisition. Bristol, UK: Multilingual Matters.

[36] Mochida, A., \& Harrington, M. (2006). The Yes-No test as a measure of receptive vocabulary knowledge. Language Testing, 23(1), 73-98.

[37] Nassaji, H. (2003). L2 vocabulary learning from context: Strategies, knowledge sources, and their relationship with success in L2 lexical inferencing. TESOL Quarterly 37(4), 645-670. 
[38] Nassaji, H. (2004). The relationship between depth of vocabulary knowledge and L2 learners' lexical inferencing strategy use and success. Canadian Modern Language Review, 61(1), 107-134.

[39] Nation, P. (1990). Teaching and learning vocabulary. New York: Newbury House.

[40] Nation, P. (1997). The language learning benefits of extensive reading. The Language Teacher, 21(5), 13-16. Retrieved March, 2010 from http://www.jalt-publications.org/tlt/files/97/may/benefits.html.

[41] Nation, P. (2001). Learning vocabulary in another language. New York: Cambridge University Press.

[42] Nunan, D. (1999). Second Language Teaching \& Learning. Boston: Heinle \& Heinle Publishers.

[43] Nyikos, M., \& Fan, M. (2007). A review of vocabulary learning strategies: Focus on language proficiency and learner voice. In A. Cohen \& E. Macaro (Eds.), Language learner strategies: 30 years of research and practice (pp. 251-274). Oxford: Oxford University Press.

[44] O'Malley, J., \& Chamot, A. (1990). Learning strategies in second language acquisition. Cambridge: Cambridge University Press.

[45] Oxford, R. (1990). Language learning strategies: What every teacher should know. Boston: Newbury House.

[46] Oxford, R. (2003). Language learning styles and strategies: An overview. GALA. Retrieved August, 2010 from http://web.ntpu.edu.tw/ language/workshop/read2.pdf

[47] Prince, P. (1996). Second language vocabulary learning: The role of context versus translations as a function of proficiency. Modern Language Journal, 478-493.

[48] Pulido, D. (2004). The relationship between text comprehension and second language incidental vocabulary acquisition: A matter of topic familiarity? Language Learning, 54(3), 469-524.

[49] Pulido, D. (2009). How involved are American L2 learners of Spanish in lexical input processing tasks during reading? Studies in Second Language Acquisition, 31(1), 31-58.

[50] Pulido, D., \& Hambrick, D. (2008). The virtuous circle: Modeling individual differences in L2 reading and vocabulary development. Reading in a Foreign Language, 20(2), 164-190.

[51] Qian, D. (2002). Investigating the relationship between vocabulary knowledge and academic reading performance: An assessment perspective. Language Learning, 52(3), 513-536.

[52] Read, J. (2000). Assessing vocabulary. Cambridge: Cambridge University Press.

[53] Read, J. (2007). Second language vocabulary assessment: Current practices and new directions. International Journal of English Studies 7(2), 105-125.

[54] Rhodes, N., \& Pugahl, I. (2009). Foreign language teaching in U.S. schools: Results of a national survey. Washington, D.C.: The Center for Applied Linguistics (CAL).

[55] Riley, L., \& Harsch, K. (1999). Enhancing the learning experience with strategy journals: Supporting the diverse learning styles of ESL/EFL students. Paper presented at the HERDSA Annual International Conference, Melbourne, Australia

[56] Rubin, J., \& Thompson, I. (1994). How to be a more successful language learner: Toward learner autonomy (2nd ed.). Boston: Heinle and Heinle.

[57] Sagarra, N., \& Alba, M. (2006). The key Is in the keyword: L2 vocabulary learning methods with beginning learners of Spanish. Modern Language Journal, 90(2), 228-243.

[58] Sanaoui, R. (1995). Adult learners' approaches to learning vocabulary in second languages. Modern Language Journal, 79(1), $15-28$.

[59] Schmitt, N. (1997). Vocabulary learning strategies. In N. Schmitt \& M. McCarthy (Eds.), Vocabulary: Description, acquisition and pedagogy. Cambridge: Cambridge University Press.

[60] Schmitt, N. (2000). Vocabulary in language teaching. New York, NY: Cambridge University Press.

[61] Schmitt, N., \& McCarthy, M. (1997). Vocabulary: Description, acquisition and pedagogy. Cambridge, UK: Cambridge University Press.

[62] Scribner, G. (2000). The effects of three methods of vocabulary memorization in second language acquisition: Rote memorization, mnemonics, and network of conceptual relations. Unpublished master's thesis, Brigham Young University, Provo, UT.

[63] Stoffer, I. (1995). University foreign language students' choice of vocabulary learning strategies as related to individual difference variables. Unpublished Doctoral Dissertation, University of Alabama.

[64] Swain, M., \& Carroll, S. (1987). Vocabulary instruction in immersion classes. In B. Harley, P. Allen, J. Cummins \& M. Swain (Eds.), The development of bilingual proficiency: Final report (Vol. 2, pp. 192-222). Toronto: Modern Language Centre, Ontario Institute for Studies in Education.

[65] Tseng, W.-T., \& Schmitt, N. (2008). Toward a model of motivated vocabulary learning: A structural equation modeling approach. Language Learning, 58(2), 357-400.

[66] Vann, R. J., \& Abraham, R. G. (1990). Strategies of unsuccessful language learners. TESOL Quarterly, 24(2), 177-198.

[67] Wenden, A. (1998). Metacognitive knowledge and language learning. Applied Linguistics, 19(4), 515-537.

[68] Winke, P. M., \& Abbuhl, R. (2007). Taking a closer look at vocabulary learning strategies: A case study of a Chinese foreign language class. Foreign Language Annals, 40(4), 697-712.

Dieter A. Waldvogel was born in El Paso, Texas, U.S.A. in 1971. He is a Spanish Instructor at the U.S. Air Force Academy, Colorado Springs, Colorado, U.S.A. (currently on assignment to Maryland). Dr. Waldvogel earned a doctoral degree in Foreign Language Education from the University of Texas at Austin in 2011. He is an active duty officer in the U.S. Air Force with specializations in Communication \& Information Systems and Foreign Area Studies-Latin America. 